\title{
WHICH FANS ARE THE BIGGEST ACCELERATION OF THE GRANDSTAND?
}

\author{
MARTIN VERnER
}

\author{
Czech Technical University in Prague, Faculty of Civil Engineering, Thakurova 7, 166 29 Prague 6, Czech \\ Republic \\ correspondence: martin.verner@fsv.cvut.cz
}

\begin{abstract}
The fans of AC Sparta Prague and SK Slavie Prague have been arguing about the fact whose fans support their team better since the end of 20th century. There have been made many experiments on the intensity of vibrations at football stadiums during matches. Altogether 11 matches were watched. Frequencies caused by the fans leadinng to vibrations and the size of those vibrations were provided from the results. Based on those facts the question about the bigger intensity of fans ${ }^{6}$ support was answered.
\end{abstract}

KEYWORDS: Vibrations, grandstands, spectators' behaviour, stadium, Czech First League.

\section{INTRODUCTION}

People like entertainment since ancient Greece. The most popular leasure time activity was theater and sport matches, especially Olympic Games. Roman Emperors tried to keep common people in peaceful mood through games and bread. This was renewed in 19 th century when a new sport appeared - football. Even Austria-Hungary favoured football clubs. There were two football clubs in Prague. AC Kralovske Vinohrady was founded in 1891. It was renamed to AC Sparta in 1894. The Academic Cyclistic Club Slavie was founded in 1892 . The club was renamed to Sport Club Slavie in 1895. Those two clubs became sport rivals from the very beginning. The fans of each club claim that they support their team in the best and most intense way and so that they provide the players with power to win the match. The fans say that they can cheer for their team in such a way that they could break down the stadium. The question is how to judge the cheering intensity in an objective way. Does the number of fans make the difference? Or is it the sound volume? Or the vibrations intensity? This article compares the fans' behaviour with the vibrations intensity made at the stadiums SK Slavie Prague and AC Sparta Prague [1-6].

\section{Circumstances influencing VABRATIONS INTENSITY}

\subsection{Stadiums CONSTRUCTION}

Vibrations intensity depends on several factors. First of all on the construction type itself.

SK Slavie Prague plays its home matches at Eden stadium, which was opened in 2008. The stadium is built on the place of original Slavie stadium where used to be a pond. It is a clasical oval stadium for approx. 20,000 spectators. The construction is made of reinforced concrete parts with steel rooftop. The

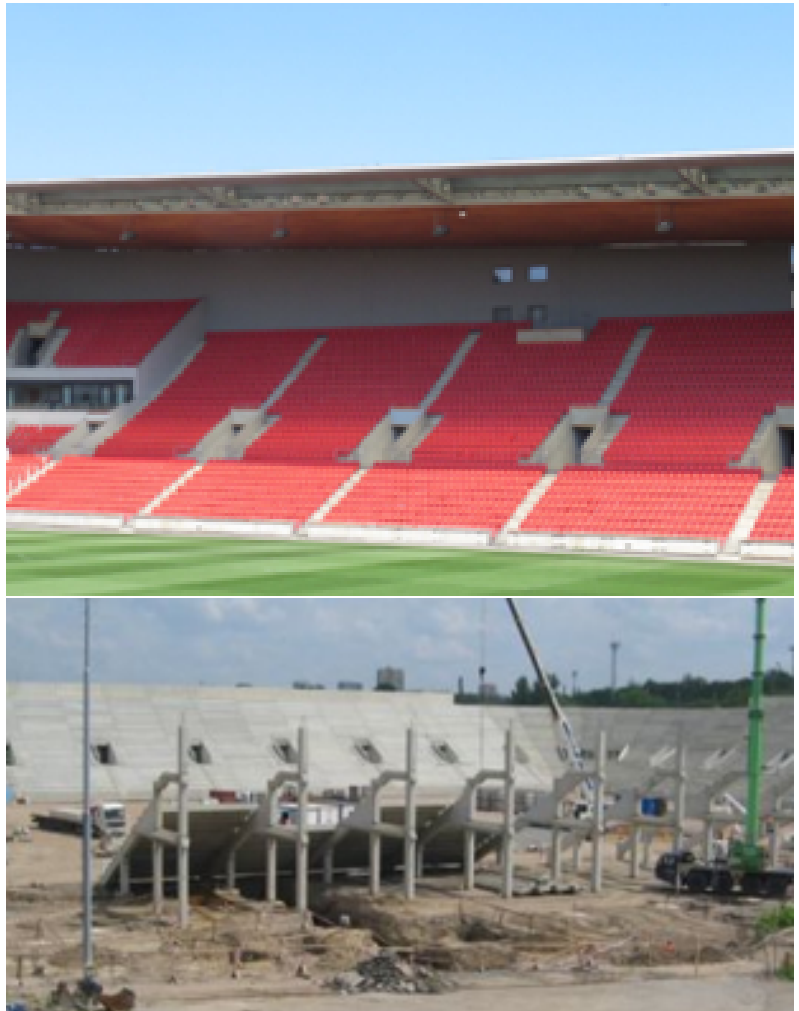

Figure 1. Platform construction: a) Eden Stadium the overall view [5], b) Eden Stadium detail [7].

platforms are made of a system of concrete crossbeams (plain crossbeams) on which reinforced concrete L-shaped panels are laid. The panels create an underpass in spectators front and there are seats for the spectators as well (Figure 1).

AC Sparta Prague plays at Letna stadium, which was reconstructed in 1994. The stadium is divided in two parts. East (main) platform was built in 1937 as a reinforced concrete construction. The other parts of the stadium are made of steelconcrete construction 


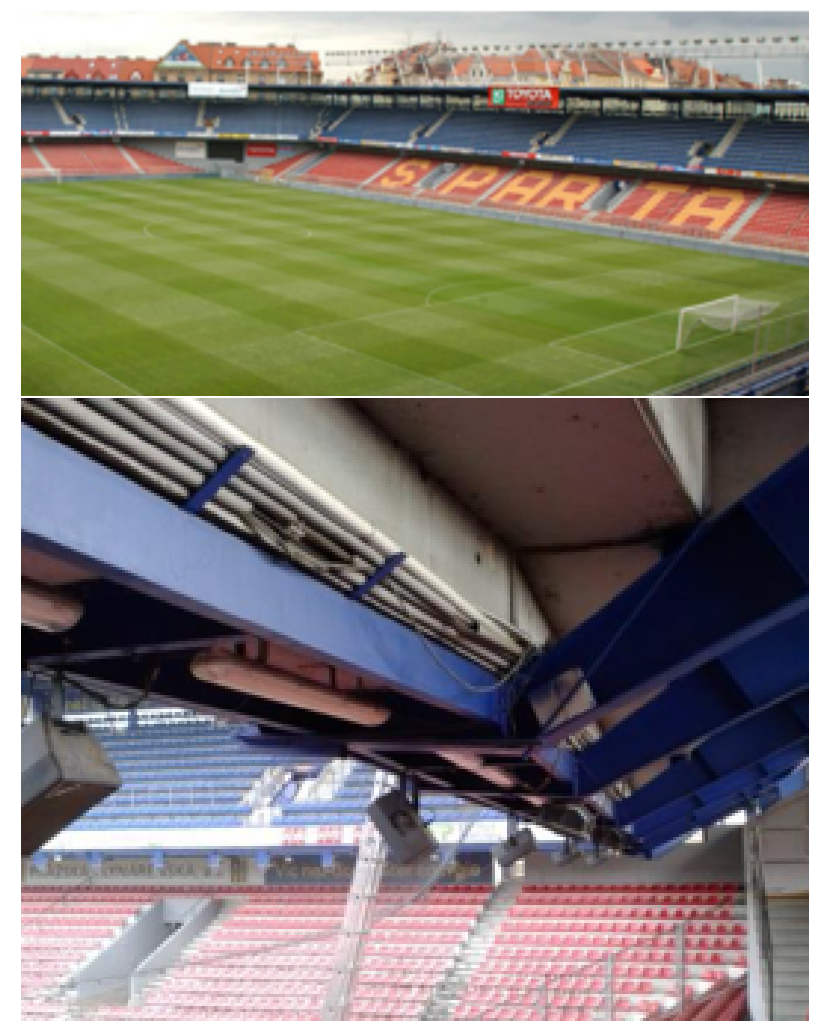

Figure 2. Platform construction: a) Letna Stadium the overall view [8], b) Letna Stadium detail [1].

and they are two storeyed. The second storey is made of steel crossbeams (a carrier beam with overhanging end) on which precast reinforced concrete L-shaped panels are laid. The roof is made of a steel framed structure (Figure 2).

It results from the text above that the platforms are similar but each of them is completely different from the dynamics point of view. Eden Stadium shows bigger vibrations intensity locally - on the concrete panels while Letna Stadium tends to show more intense vibrations of the concole part of the platform as a whole.

\subsection{FANS ${ }^{6}$ BEHAVIOUR}

\subsubsection{ULTRAS}

the response of the most active fans was observed on the stadiums. These fans meet in a particular sector of stadium and are called "ULTRAS". "ULTRAS" are the type of fans who ultra-fanatically support their football club. The mark of their behavior is using of flares (primarily as part of choreography), loud group cheering and creationing of giant banners in football stadiums that serve to create a stormy atmosphere on matches. The behavior is used to encourage their own team, intimidate opponents and fans of their opponents. The other major features include the inclination to ultra-right and racism. "ULTRAS" are located on the North granstand on the stadium in Eden (3). Fans use pyrotechnics to a lesser extent and are among the quieter fans in the Czech Football
League. Letna's "ULTRAS" (4) are the exact opposite type of fans. They are one of the most problematic fans in the Czech Republic. They use pyrotechnics a lot, they are fighting and the club itself is often fined for their behavior (pyrotechnics are prohibited in the stadiums in the Czech Republic) and their space is closed during the match at least once a season.

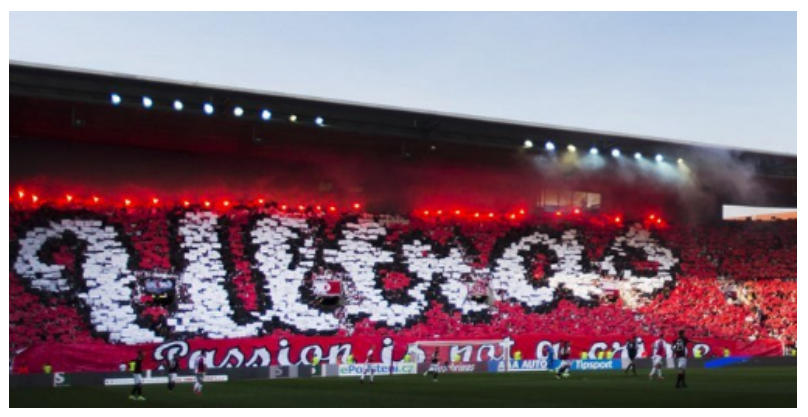

Figure 3. ULTRAS at Eden Stadium 9.

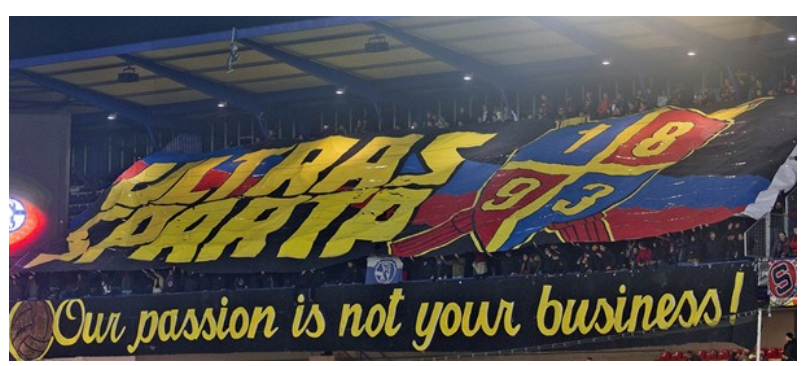

Figure 4. ULTRAS at Letna Stadium [10.

\subsubsection{FAN BEHAVIOR FROM A DYNAMIC RESPONSE VIEW}

Another factor influencing the vibrations intensity is the fans themselves. The basic parametre concerning the fans is the number of them. Then it is their behavoiour. Their behaviour can be divided into two categories - the behaviour in general and the behaviour on the platform. The Czech spectator is very specific. When the team plays well, the fans cheer with higher intensity and attend the stadium in bigger quantitites. In case the club goes through worse time, the number of the spectators and the intensity of their support decline. The behaviour on the platform itself can be divided into several categories. There are two types of relevant jumping - type 2 and type 3 for our needs of comparing vibrations.

The jumping type 2 is defined as follows: The spectators stand on the platform. The whole rows of spectators catch each other's shoulders under the direction and start jumping on the spot. It leads to a quick synchronization of the spectators and, according to the results of the experiments, to the most intense construction stimulation.

The jumping type 3 is defined as follows: Likewise type 2 the fans stand on the platform and catch each other's shoulders. They start jumping. Type 2 differs 
from type 1, they do not move just up and down and also horizontally.

From the dynamics point of view the position of the fans on the platform is crucial. Slavie fans stand on concrete panels. Sparta fans are on the second storey of the platform on the concole part of the beam [1, 6 .

\subsection{MeAsUREMENT WAY}

\subsubsection{Monitoring the SPECTATORS}

The entire ULTRAS's sector was monitored using a video camera at both stadiums. The camera was located at a sufficient distance from the sector due to security of cameraman. Fans do not like when someone shoots them. The camera was approximately 100 meters from the sector at the stadium in Eden. Letna was located at $85 \mathrm{~m}$.

\subsubsection{MONITORING THE ACCELERATION OF THE GRANDSTAND}

The vibrations intensity was measured by acceleration sensors (Bruel and Kear type 4507 B005). There were used four sensors in total. Three of them entered vertical acceleration and one of them entered horizontal acceleration. At Eden the sensors were placed onto a concrete panel (vertical + horizontal) and onto neighbouring crossbeams (Figure 5 At Letna only the vibrations of console steel beams were tracked. From the technical point of view it was not possible to place the sensors onto concrete panels safely [1]

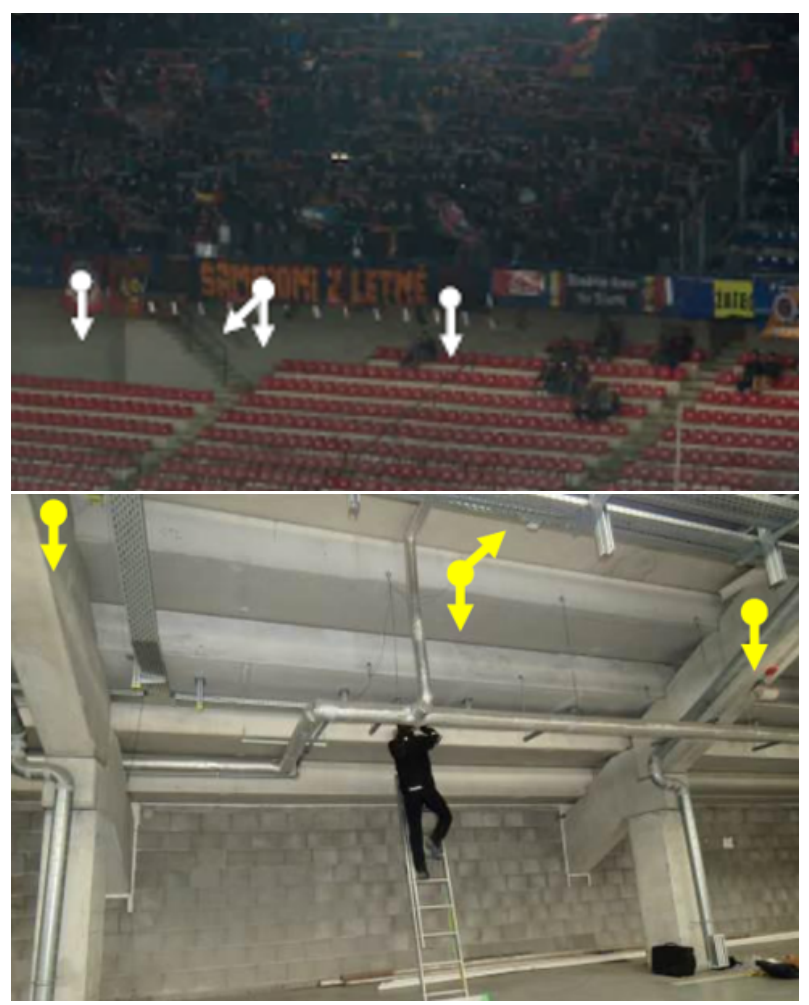

Figure 5. Sensors placement: a) Letna Stadium [1, b) Eden stadium 4 .

\section{OBservation PERIOD}

Three experiments were observing the platform vibrations intensity during football match. The first measurement was done at Letna in 2013 followed by measurements at Letna in 2015 and at Eden in 2016.

\subsection{Letna Stadium 2013}

The observation was done during two football matches at the end of the autumn part of the 2013/2014 season. It was at that time when AC Sparta Prague won the autumn. There was not a camera watching the behavior of individual spectators. At the same time, only the vertical vibrations of the platform were recorded (there was no horizontal sensor). The fans managed to drive an acceleration of $1.96 \mathrm{~m} \cdot \mathrm{s}^{-2}$ at drive frequency $2.35 \mathrm{~Hz}$ (Figure 6 and 7). The acceleration was recorded after the end of the second match when the fans celebrated the victory in the middle of the competition. It resulted from the experiment that it should have been caused by jumping of the entire rows vertically [1, 3,6 .

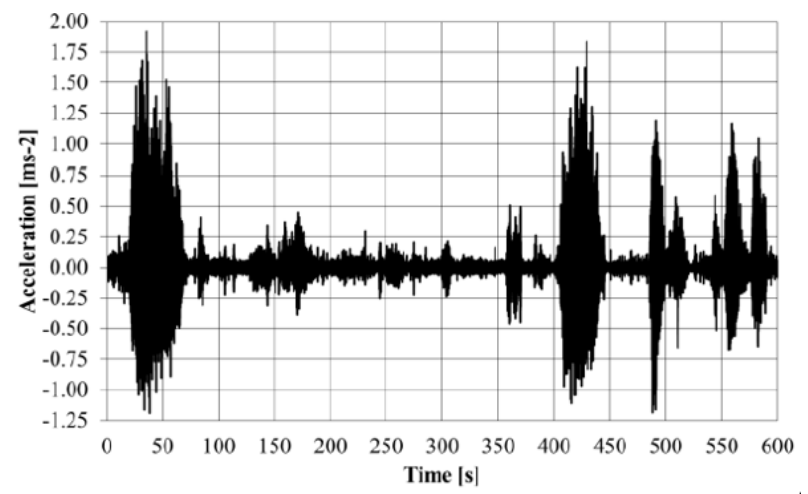

FiguRE 6. Maximum platform acceleration in 2013 [2].

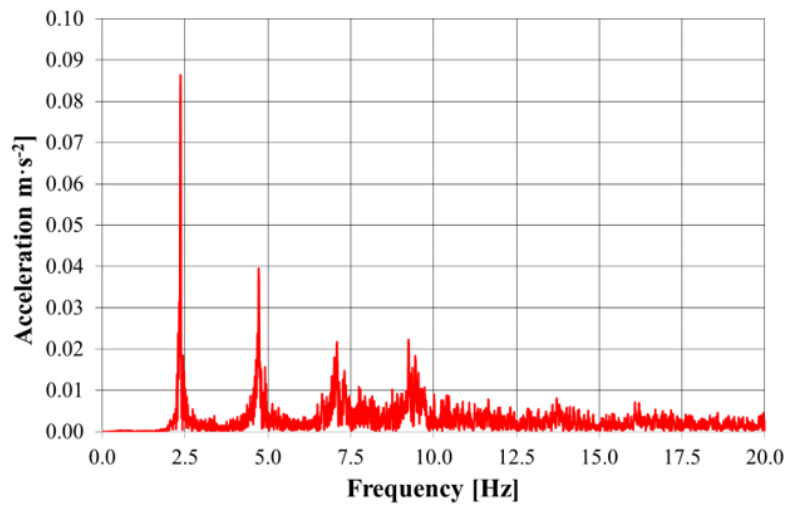

Figure 7. Frequency at Letna in 2013 [6].

\subsection{Letna Stadium 2015}

The second observation was taken in the spring part of the competition of $2014 / 2015$ season. In total 5 matches were observed. In contrast to the previous experiment a horizontal acceleration sensor was added. There was also a camera used to watch the fans' behaviour. The season was not successful for Sparta at 
all. As the end of the competition was approaching the placement of the club was clear. Gradually the number of spectators was decreasing and the level of vibrations was dropping down as well. The biggest vertical acceleration $\left(1.96 \mathrm{~m} \cdot \mathrm{s}^{-2}\right.$ at drive frequency of $2.5 \mathrm{~Hz}$ - Figure 8) was observed during the third observed match. The video record showed that it was caused by jumping of individual rows vertically [1, 3,6 ,

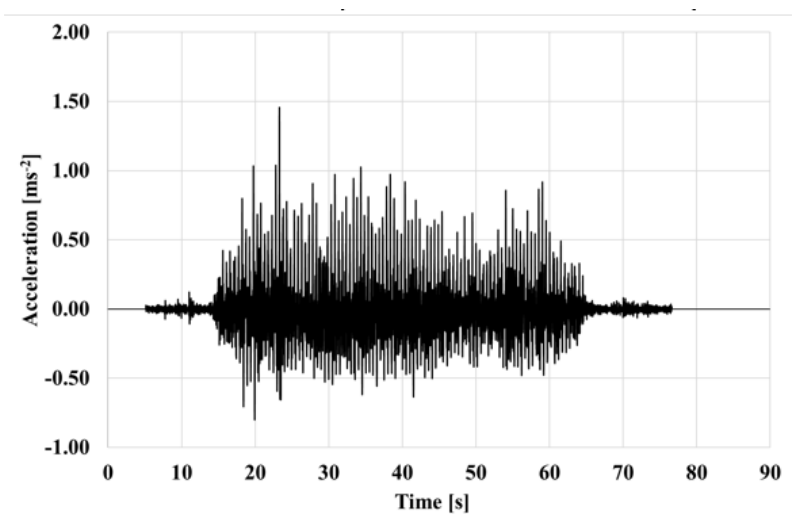

FiguRE 8. Maximum platform acceleration in 2015 [6].

\subsection{Eden Stadium}

The last football matches observation was taken at Eden. Again, the spring part of the competition of 2015/2016 season was observed. Four matches were specific. The experiment was done at Letna as well as the previous ones. Slavie was going through a financial crisis at that time. Right before the start of the competition a new investor came to the club who tried to stabilize the club. The visit rate dropped down significantly after the firts match. The biggets vibrations were recorded during the first match $\left(2.84 \mathrm{~m} \cdot \mathrm{s}^{-2}\right.$ at drive frequency of $2.17 \mathrm{~Hz}-$ Figure 9 and 10 . It was caused by jumping of the vertical rows. Second biggest vibrations were, again, recorded during the first match $\left(2.35 \mathrm{~m} \cdot \mathrm{s}^{-2}\right.$ at drive frequency of $\left.2.18 \mathrm{~Hz}\right)$. This was measured during jumping of individual rows horizontally [4, 5]

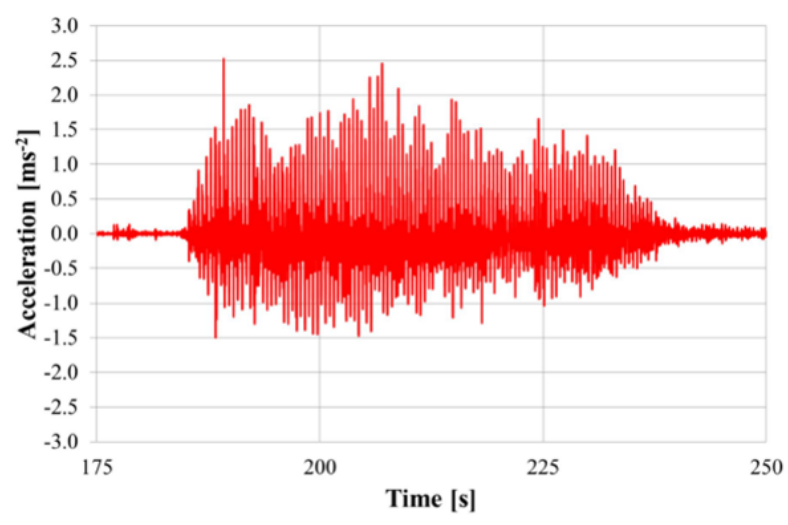

Figure 9. Maximum platform acceleration in 2016 [4].

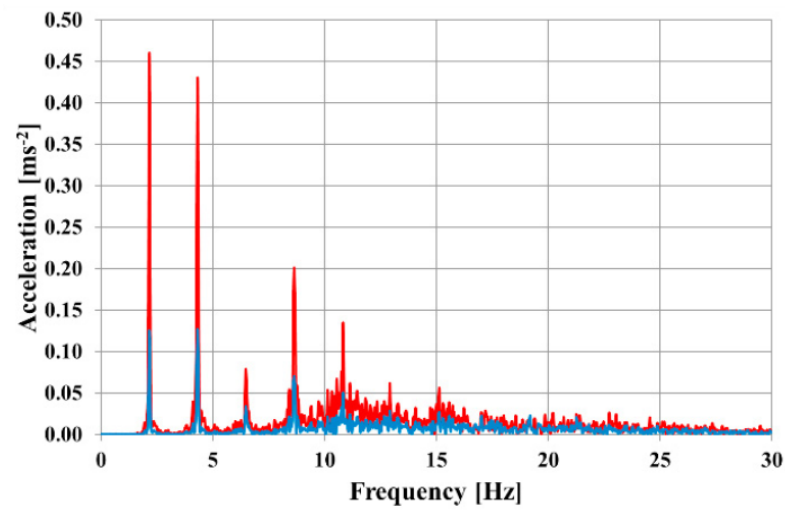

Figure 10. Frequency at Eden in 2016 [5].

\section{Conclusions}

When considering only the absolute strenght of vibrations the most active fans are those of SK Slavie. As mentioned in chapter 2 . the sensors at Letna were not laid in concrete panel. Unlike Eden the vibrations of the entire platform were recorded resulting in the fact that the AC Sparta fans could be the most active ones. It is not good to compare the results just through the vibrations level because the constructions inluded in the experiments were of different dynamic features. The only way to compare the activity is though the drive frequency caused by the fans. When having a look at the drive frequencies and material composition of the platforms (vibration dampening capacity influence) it is clear that the fans drove with the same intensity. Maximum drive frequncy was very similar during both matches. The answer to the question asked at the beginning is that the fans - from the dymacics point of view - support their teams with similar intensity.

\section{ACKNOWLEDGEMENTS}

The research was financial supported by the Faculty of Civil Engineering at CTU in Prague (SGS project No.16/201OHK1/3T/11) and the Czech Science Foundation project No. GA15-15728S.

\section{REFERENCES}

[1] M. Verner, T. Plachy, M. Polak. An experiment focused on fans behaviour and induced grandstand vibrations during a football match. Trends in Statics and Dynamics of Constructions II ZÃijrich: Trans Tech Publications Offices LTD pp. 75-78, 2016.

[2] M. Verner, M. Polak, T. Plachy. An experimental analysis of grandstand vibrations caused by crowd of spectators during two football matches. Aplied Methods of the Analysis of Static and Dynamic Loads of Structures and Machines II Zurich: TRANS TECH PUBLICATIONS LTD pp. 312-315, 2016.

[3] V. Martin. Behaviour of fans during the football match. Modern Methods of Experimental and Computational Investigations in Area of Construction Pfaffikon: Trans Tech Publications Inc pp. 77-80, 2016. 
[4] T. Plachy, M. Polak, M. Verner. Comparison of the fans behaviour and the induced grandstand vibrations on two different football stadia. DYNAMICS OF CIVIL ENGINEERING AND TRANSPORT STRUCTURES AND WIND ENGINEERING (DYN-WIND'O017) 2016.

[5] T. Plachy, M. Polak, M. Verner. An experimental study focused on spectators' behavior and induced vibrations of a reinforced concrete grandstand on a football stadium. Procedia Engineering Oxford: Elsevier Ltd) pp. 2871-2876, 2017.

[6] M. Polak, T. Plachy, M. Verner. A comparison of spectators induced grandstand vibrations and fans behavior during two football matches between the same teams. 54th International Conference on Experimental Stress Analysis 2016 p. 6, 2016.

[7] KONSTRUKCE Media, s.r.o. Stadion eden - postup praci 2005. http://www.konstrukce.cz/clanek/ stadion-eden-postup-praci/
[8] EMPRESA MEDIA, a.s. Zemrel architekt mandel, kterz navrhl stadion sparty 2011. https:

//www.tyden.cz/rubriky/lide/ceske-celebrity/ zemrel-architekt-mandel-ktery-navrhl-stadion-sparty_ 214905.html

[9] MAFRA, a.s. Ultras eden. choreo slavistickych fanousku behem derby.

https://fotbal.idnes.cz/foto.aspx?r=fotbal\& foto1=T0F6a5d61_183459_1597445.jpgl.

[10] MAFRA, a.s. Sparta vs. lazio, plne tribuny, novinari $\mathrm{z}$ nemecka a hsote bez treninku.

https://fotbal.idnes.cz/

sparta-lazio-rim-osmifinale-evropske-ligy-fi8fot_pohary.aspx?c=A160309_150622_fot_pohary_ min. 